\title{
Creation of Adaptive LMS Systems in Postgraduate Education
}

\section{Hanna Sokhatska*}

\begin{abstract}
The article considers the development of the market for postgraduate education in the context of requirements of Industry 4.0. The composition of the main providers of the educational services market has been determined. Among them are groups of universities, consulting and educational centres and business schools. The most significant for retraining of personnel are traditional universities and corporate training centres. They allow to effectively achieving students the required level of competence through a highly specialized training program. Universities also build a curriculum based on a competence-oriented approach. However, in fact, the actual needs of business in qualifying personnel are insufficiently taken into consideration in state education standards, which leads to the labour market imbalance. For adapting the existing training system to the new conditions a flexible LMS model has been proposed. It is based on the interaction of business, training centers and the labor market (student). Filling the LMS in such an 'ecosystem' occurs in accordance with the needs of enterprises in the field of qualification of the necessary personnel. As a result, the university or training center provides the necessary tools in the modular LMS, taking into account the prospects for the development of markets in the Industry 4.0. The student sets up the LMS for his individual needs and obtains precisely those skills and competencies that will enable him to become a competitive employee. Therefore, the company receives qualified personnel with a set of necessary competencies. Such an 'ecosystem' allows a flexible adaptation of the content of the educational process to the needs of all participants in the training. Using the proposed approach will ensure sustainable competitiveness of companies by providing the necessary personnel, students - to get the most popular skills and high qualifications, and training centers - to ensure high quality and demand for their educational services.
\end{abstract}

Key Words: LMS, competences, labor market, teaching methods, postgraduate education, qualification, Industry 4.0.

\section{Introduction}

Over the past decades, global transformations have occurred in the world, linked to the new technological paradigm. Total informatization of economic processes definitely affects such an important sphere of human activity as education. The labour market today prefers professionals with a high level of communicative and leadership qualities that can handle non-standard tasks and combine different areas of knowledge. The digitization of the economy and the rapid development of innovation require a continuous updating of the set of professional competencies to meet the needs of the market.

The modern model of vocational training is in the process of transformation, which actively involves the state and educational institutions. At the same time, there are certain imbalances in the system of higher education, which require further elimination. Thus, there is a chain between the employer and the supplier of staff (an educational institution) that is not flexible

\footnotetext{
${ }^{*}$ Kyiv National University of Technology and Design, Ukraine Corresponding Email: ansinf2014@gmail.com
} 
enough and not well adapted to changing competitive conditions. But sometimes bureaucratized management systems are not directly responsible for the professional employment of graduates.

Vocational training requires the further development of a lifelong learning system that will meet the needs for retraining or upgrading of workers at different levels in line with rapid information and technological transformations in the economy and society. An important role in the training of such specialists is played by the system of postgraduate education and corporate training. The current situation on the labour market is characterized by the availability of several alternative sources of education and practical skills in a particular field. Among them are classical universities, open online education systems, independent and corporate training centres. All these structures rely on the process of providing services to LMS as the main platform for the interaction of all participants in the educational process.

\section{Methodology}

The modern vector of development of the educational market is characterized by a clear orientation on labour market demands regarding the required set of professional competencies of employees. At the same time, traditional patterns of teaching at universities do not always provide future professionals with a sufficient level of mastering the necessary competencies.

Despite the development of the information environment, modern educational systems remain, unfortunately, still quite conservative, which prevents them from adequately competing with leading educational institutions in the international environment. But reforms in the economy and the education system, as well as increasing the competitive pressure of alternative players in the educational market, encourage them to look for new managerial decisions that are more adapted to the current and future requirements of the labour market, since their graduates must develop a high-tech economy of the future, the key characteristic of which is uncertainty and variability. The modern system of training and retraining of personnel should quickly adapt to the new requirements, creating favourable conditions for the formation of positive perceptions of changes, creative approach and non-standard thinking in specialists dealing with solving professional tasks, the ability to manage information flows and the ability to obtain reliable data in non-standard conditions (Sokhatska, 2017a).

However, the real state of the domestic labour market shows that there are certain imbalances in the area of personnel upgrading and retraining. So, on the one hand, there is a lack of young management specialists' practical experience in quickly solving practical problems in the workplaces, on the other hand, domestic employers in most cases seek an already experienced specialist who is able to deal with complex professional tasks quickly and efficiently, and, accordingly, have no desire to lose time and money on training and retraining of interns. This situation creates the grounds for reducing the share of employment in the specialty of graduates of higher education and a certain depreciation of higher education in society.

In search of answers, the domestic labour market is trying to find alternative ways to ensure the quality training of management personnel, referring to other sources of knowledge supply. Recently, the Ukrainian educational market has seen a significant increase in competition among leading providers of educational services, driven by the trends of globalization and academic mobility of scientific staff, the development of the corporate sector of postgraduate education, and the spread of trends to self-education through open online resources.

The current state of the market of post-graduate education providers can be presented in Fig. 1. 


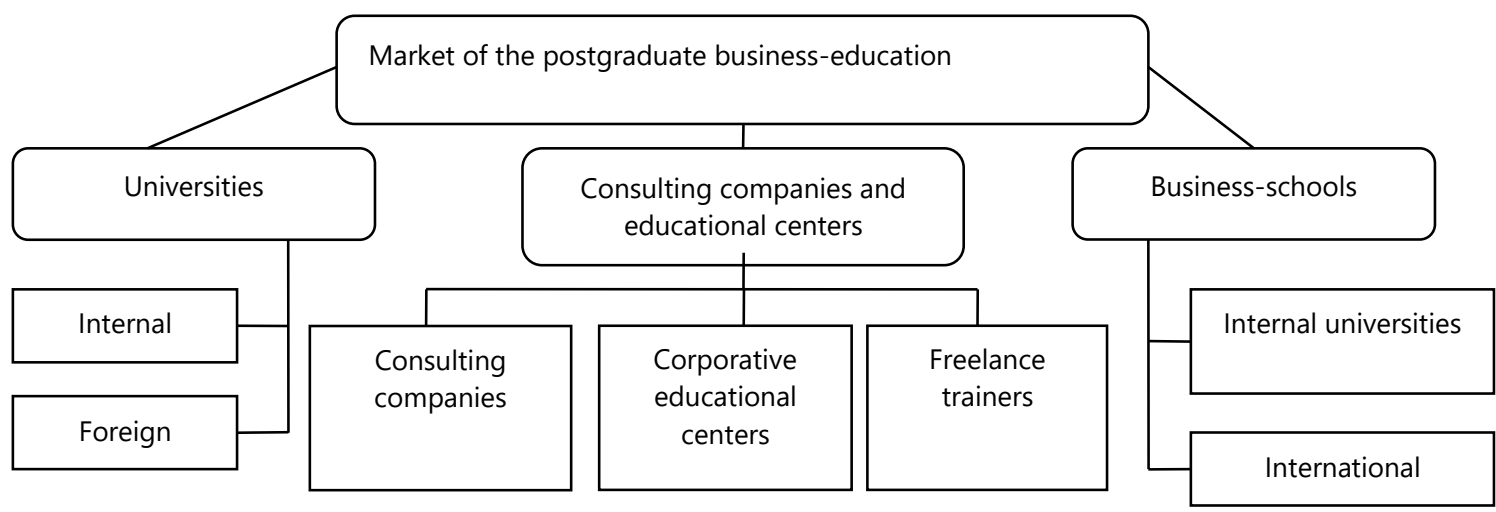

Figure 1: Generalized structure of the postgraduate business-education in Ukraine (Sokhatska, 2016, p. 119).

As one can see, the educational market is quite saturated and actively developing. At the same time, the methodology of training in different market players has fundamental differences. Postgraduate education at universities is based on traditional educational instruments that practically repeat the methodology of basic higher education. This is a holistic system that has a significant historical background, a significant scholarly contribution and a broad theoretical foundation.

An important role in shaping the modern educational system in Ukraine is played the European educational policy, which needs to be harmonized with the national standards of education. The successful experience of the European Union countries shows that it is necessary to form not only educational system elements but also the implementation of a comprehensive Education and Training 2020 strategy (European Commission, n.d.).

The modern educational system in Ukraine is based on the introduction of national standards of higher and vocational education on the basis of the NFQ, approved by the Ministry of Education and Science of Ukraine. Schematically it is possible to represent it in the form of such elements (Fig. 2).

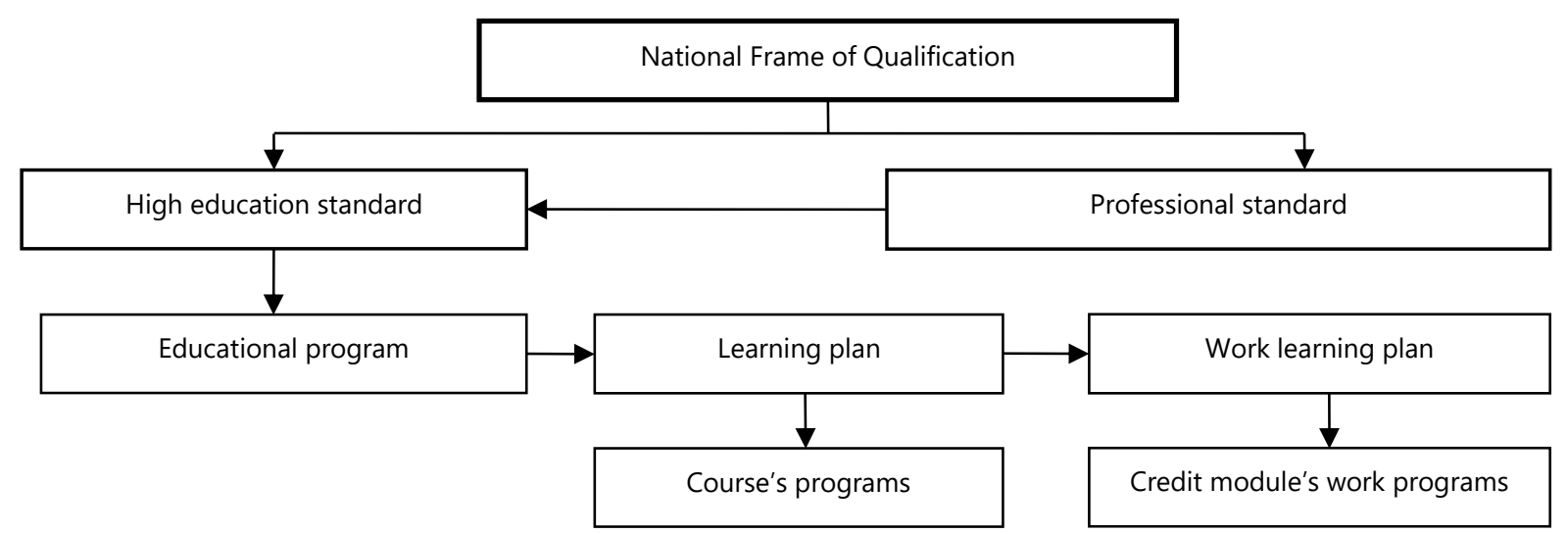

Figure 2: Structure of educational content development (adapted based on Law, 2017)

According to the given scheme, the primary source of requirements for the future specialist is the approved standard of education. Educational institutions (universities) and the state are represented in the institution by the relevant institutions in its creation. At the same time, for the effective functioning of the proposed standards, it is necessary to involve business 
representatives who act as consumers for the education market. Today, ties in the state-university-business triangle in Ukraine are still underdeveloped (Etzkowitz, 2008).

At the heart of modern higher education in many European countries and Ukraine there is an approach aiming at obtaining a student with a certain competency-based education. As noted in (Antonyuk et al., 2016, p.13), "competence-oriented education is aimed at responding to the personal, social, professional and cultural needs of modern society. In this direction, there is a transition from a traditional approach in which teaching is centred, to an education oriented, where students are the centre of the educational process". Consequently, competence-oriented learning is closely linked with the implementation of the principles of activating the learning process, according to which students must themselves collect information for problem solving. This changes the role of 'teacher-student' (ibid, p.26).

An important place in the LMS study is the structure and content of competencies that should be provided by its elements. User guide for the European Credit Transfer System (ECTS) (European Commission, 2015), the main competencies are defined at different levels of qualification, but there is no single interpretation of these categories, and this situation is natural in the conditions of rapid changes that are the inherent requirements of business, which cannot be a priori standardized within the global markets, so the educational system should have a large flexibility reserve for rapid adaptation to labour market demands. Thus, it is expedient to see the introduction of a flexible adaptive education system, the elements of which are customized and business queries.

However, despite the relatively long implementation of such an approach to the Ukrainian system of higher education, in practice it remains incompletely implemented. In the higher education system, there are objectively similar phenomena, such as conservatism, insufficient level of information culture of personnel, lack of international experience, which considerably complicate the process of integration of Ukrainian universities into the international educational system. However, modern teaching requirements include the presence of a high level of technological awareness among the instructor, openness to advanced innovative technologies and the ability to integrate them into their everyday practice, as well as a decent logistical support of the educational process. However, it is these abilities that create a favorable environment for the development of students' creativity, the formation of the most sought after-graduation skills of a future specialist, namely, ability to solve complex problems, critical thinking and creative abilities, the development of emotional intelligence, etc. (Sokhatska, 2017b).

\section{Results}

According to research results of scientific works and experience of leading universities, it has been found that the modern system of postgraduate education is based on the implementation of a complex LMS. The distinctive features of such a system are e-learning, the active use of modern technologies in the educational process, changing the format of interaction between the student and the teacher, the practical orientation of the educational process. Such systems are actively being implemented in the sector of corporate vocational training and in advanced universities with well-developed information infrastructure and relevantly skilled personnel. Technological opportunities for achieving such a level of development of LMS require an active use of cloud technologies, tools of virtual and complementary reality. In general, LMS can be represented as in Fig. 3 . 


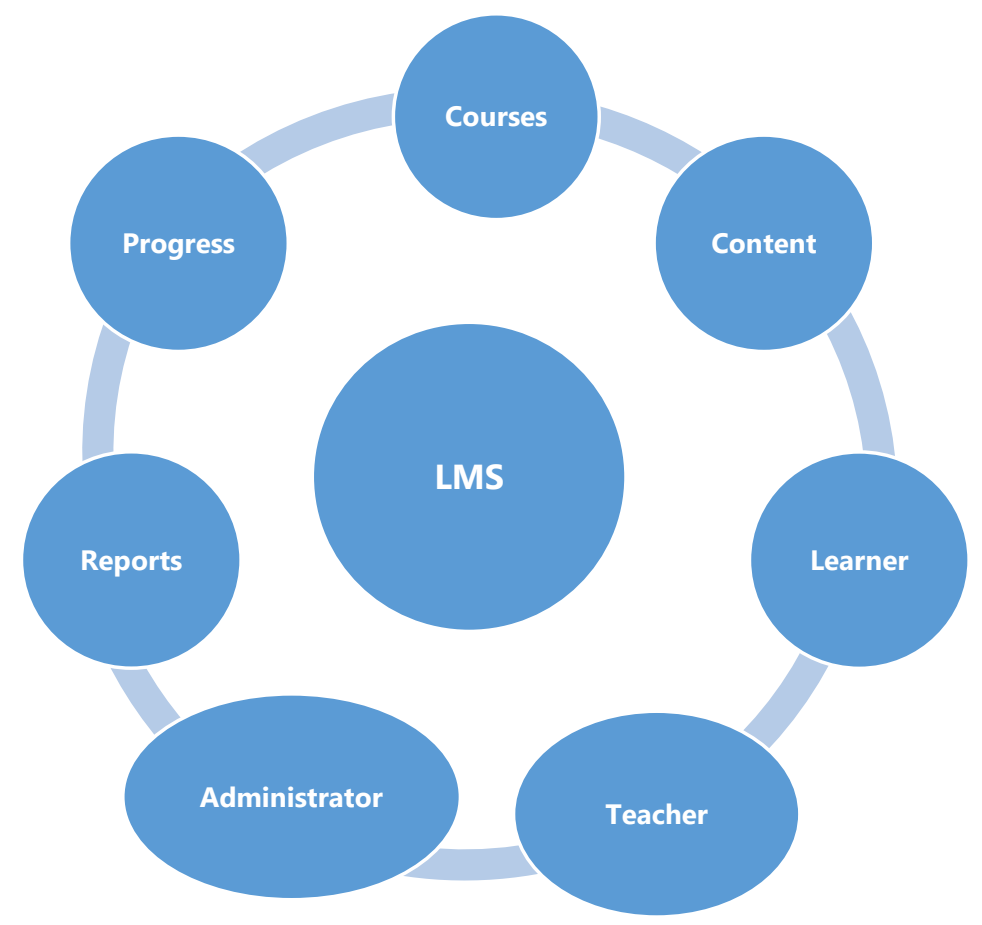

Figure 3: LMS general structure

The given structure implies filling the system of learning with a variety of content, the availability of the transparency of the educational process and an individual approach to the choice of courses and levels of complexity. But for the development of specific skills and competencies required by the labour market in the Industry 4.0, the overall structure needs to be improved (Huba \& Kozák, 2016).

According to the results of recent studies (Schallock, 2018), the most promising methods of training are still those that allow obtaining complex competencies in the following areas:

- Technical (computer skills and knowledge of modern information technologies);

- Professional (specific competences in the professional field, ability to apply interdisciplinary approach, non-standard problem solving);

- Social (teamwork, knowledge transfer, knowledge acquisition, collaboration for synchronization of processes and delivery dates)

The analysis of world contemporary trends in the educational process and the skills of a future specialist, according to the forecasts of the World Economic Forum (2018), allowed to reveal the causal relationship between the teaching methods and the skills that will ensure competitiveness in the labour market in several years According to the results of the study, three groups of teaching methods are distinguished according to the degree of novelty and the complexity of implementation in the system of the national higher education:

1 - simple: Teach back, productive error, regulatory analysis, multilingualism;

2 - medium: Crowd sourcing, learning through social media, gamification, blended learning; 
3 - complex: learning for the future (virtual, augmented reality), smart factories, block chain for learning, which involves a special technology for storing, checking and transferring ownership of the intellectual achievements of each participant in the educational process.

The introduction of such methods into a complex LMS is advisable by the principle of adaptability, which involves the use of separate methodological sets depending on the purposes and conditions of the system.

Taking into account the necessity of developing professional competences for the needs of the real and future labour market, the formation of LMS should take place in an organic combination of the interests of all participants in the educational process. This approach involves the creation of a comprehensive educational ecosystem, in which the educational institution does not offer the content of educational process tools, based on its own capabilities and state guidelines, and adjusts the necessary elements of the system to specific business demands. The role of the state in this process is to stimulate the innovation activity of educational institutions to ensure the high quality of the provision of scientific and educational products (Sanchez-Gordon $\&$ Lujn-Mora, 2015). The generalized scheme of the proposed educational ecosystem is shown in Fig. 4.

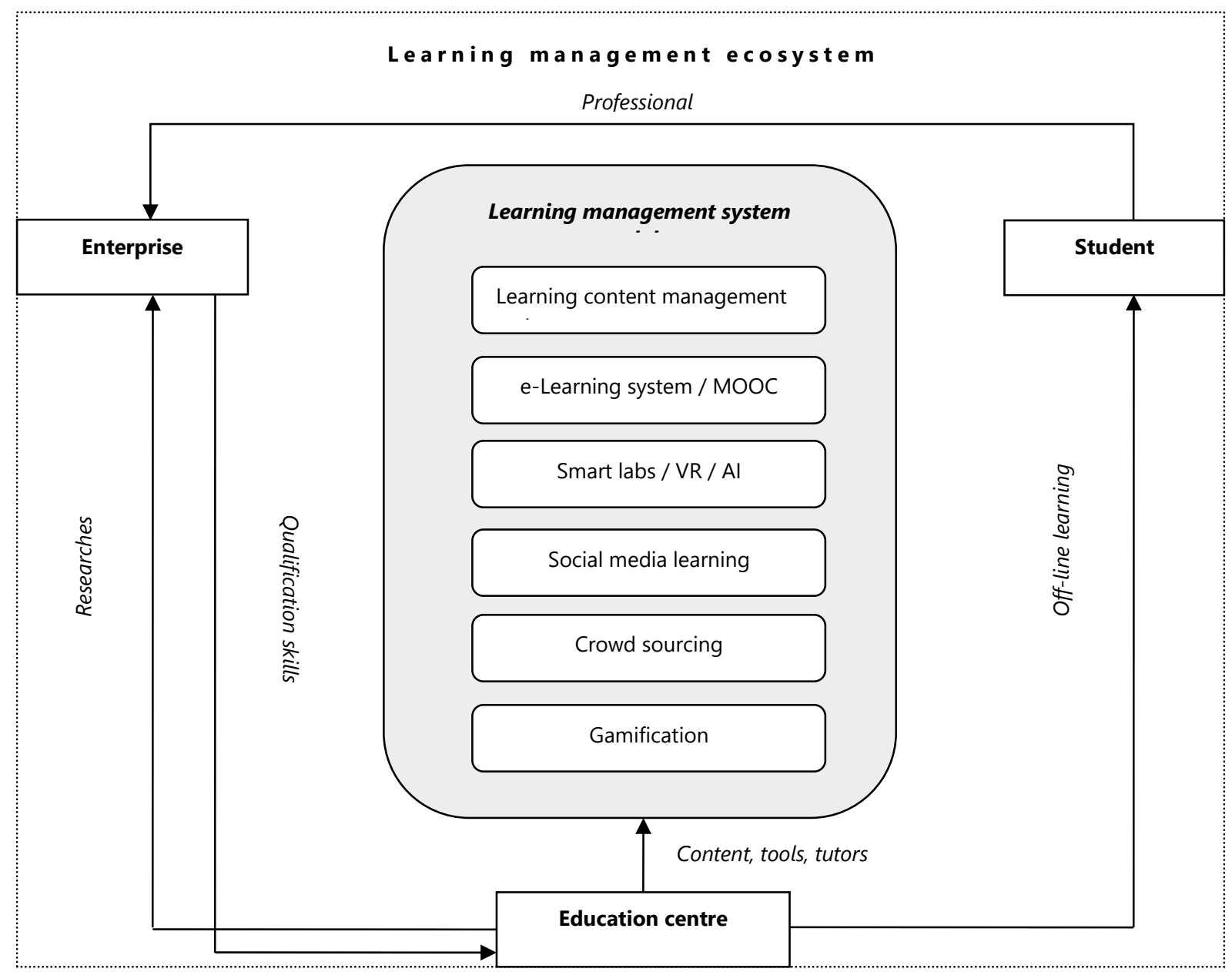

Figure 4: Learning management ecosystem 
The proposed scheme combines the main participants in the educational process in a cyclic way, which ensures the continuous supply of skilled personnel to the labour market. This approach allows you to modify the LMS configuration for specific market requests and integrate new elements according to the needs of the Industry 4.0. As a result, a balance is struck between the needs of the economy in the skilled staff and the number of graduates of post-graduate education centres, including from the number of universities.

\section{Conclusion}

The practice of introducing LMS elements into the learning process in different educational structures varies considerably depending on the field and scale of application. For example, structural subdivisions of postgraduate education at universities have long been engaged in raising their qualifications in relevant educational programs. This process is well standardized and based on state-level education standards. But for a number of reasons, services are not always able to provide high-quality training of modern specialists in accordance with business requirements.

To overcome this imbalance in the market of educational services, alternative providers of educational services are actively developing, which satisfy the urgent needs of the labour market in specialists with modern competencies to meet the challenges of the new technological era. These are various training centres, internal corporate universities, non-formal education institutions, and so on.

The basis of the activities of any educational centres is LMS, which may have a standard or specific structure. In order to achieve the correspondence between the content of training and the needs of the labour market, it is advisable to create an adaptive Learning management ecosystem that combines the business university - labour resources triad in a mutually beneficial cycle. The basis of such an ecosystem is the LMS, which will have a set of state-of-the-art training tools to provide competences for the future. The choice of a particular set of tools depends on the demand for the labour market in the certain time.

\section{References}

Antonyuk, L., Vasilkova, N., Inytsky, D., Kulaga, l., Turchaninova, V. (2016). Competently approach to higher education: world experience. Institute of Higher Education, KNEU named after V. Hetman.

Etzkowitz H. (2008). The Triple Helix: University-Industry-Government - Innovation in Action. New York \& London: Routledge.

European Commission. (2015). ECTS Users' Guide. Retrieved May 20, 2019 from https://ec.europa.eu/education/ects/usersguide/docs/ects-users-guide_en.pdf

European Commission (n.d.). Education and training. Access Mode: http://ec.europa.eu/education/policy/higher-education_en

Huba, M. \& Kozák, S. From E-learning to Industry 4:0. Bratislava, Slovakia: .Slovak University of Technology.

Sanchez-Gordon, S., Lujn-Mora, S. (2015). An Ecosystem for Corporate Training with Accessible MOOCs and OERs. IEEE 3rd International Conference on MOOCs, Innovation and Technology in Education (MITE) National Polytechnic School, Quito, Ecuador.

Schallock, B., Rybski, Ch., Jochem, R., \& Kohl, H.(2018). Learning Factory for Industry 4.0 to provide future skills beyond technical training, Procedia Manufacturing, Manufacturing Engineering Society International Conference, 23, 27-32. 
Sokhatska, H. (2017a). Formation of integrated educational structures to ensure the competitiveness of staff. Bulletin of KNUTD, Series „Economics”. 6(117): 14-21.

Sokhatska, H. (2017b). Prospects for implementing advanced information and communication technologies in the educational process. International Scientific Journal "Acta Universitatis Pontica Euxinus", Special Issue. Vienna, Austria, p. 153-157.

Sohatska, G.V. (2016) Implementation of innovations as a way to provide competitive advantages at the postgraduate businesseducation market. In Illiashenko, S.M., Strielkowski, W., eds. (2016). Managing economic growth: marketing, management and innovations. Implementation of innovations as a way to provide competitive advantages at the postgraduate businesseducation market: 117-128. Prague Institute for Qualification Enhancement, Czech Republic.

The Law of Ukraine "About Education". (2017). Information from the Verkhovna Rada. 38-39: 380.

World Economic Forum (2019). Education and Skills. Retrieved May 20, 2019 from

https://www.weforum.org/agenda/archive/education/ 